\title{
Effects of planting patterns on biomass accumulation and yield of summer maize
}

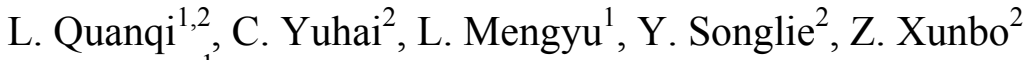 \\ \& D. Baodi ${ }^{1}$ \\ ${ }^{1}$ Center for Agricultural Resource Research, \\ Institute of Genetic and Development Biology, \\ Chinese Academy of Sciences, Shijiazhuang, P.R.China \\ ${ }^{2}$ Agronomy College of Shandong Agricultural University, \\ Tai'an Shandong, P.R.China
}

\begin{abstract}
Biomass accumulation by crops depends on both light interception by leaves and on the efficiency with which the intercepted light is used to produce dry matter. Our aim was to identify which of these processes were affected for summer maize field crops grown under different planting patterns. In this paper, the effects of different planting patterns on the radiation-use efficiency (RUE) was investigated. The experimental work was carried out in 2005 in the field located in Shandong province, north China. Three planting patterns have been applied in 2005: flat planting, bed planting and furrow planting. Above-ground biomass accumulation and grain yield of bed and furrow planting patterns were higher than that of flat planting patterns. The lower biomass production and yield in flat planting patterns was accounted for by the reduced amount of photosyntheticlly active radiation (PAR) absorbed by the canopy, which was itself the consequence of the reduced leaf area index. These results obtained in field crop conditions strengthen the idea that planting patterns greatly affect radiation-use efficiency, biomass accumulation and yield of summer maize in north China. Keywords: planting pattern, radiation-use efficiency, yield, summer maize.
\end{abstract}

\section{Introduction}

In field crop studies, the approach developed by Monteith [1] makes it possible to analyse biomass production as the consequence of two major processes: (i) the 
interception by leaves of the incoming photosynthetically active radiation and (ii) the ability of plants to transform the intercepted radiation into biomass. Environmental factors, which limit crop growth, may act through a reduction of one of these two processes, or sometimes through a combination of both. The fraction of the incoming photosynthetically active radiation that is absorbed by the canopy mainly depends on the leaf area index and crop geometry. The crop's capacity to transform the absorbed photosynthetically active radiation into biomass is called the radiation-use efficiency (RUE). It is generally estimated by the slop of the linear relationship between the above-ground biomass produced and the cumulated PAR. The physiological processes underlying the RUE have been reviewed by Kiniry et al [2], Russell et al [3], Sinclair and Muchow [4]. Sinclair and Horie [5] have calculated that increasing the leaf photosynthesis rate increases the RUE non-linearly, with the RUE reaching a maximum value at high photosynthesis rate. Other analysis has indicated that stresses that reduce the leaf photosynthetic rate should result in lower RUE. Such as the case for nitrogen, which was shown to affect the RUE of maize [6].

The current economic milieu of developing countries and its effects on the agricultural sector, particularly in the search for sustainable agricultural systems, has changed cultivation patterns as well as agricultural practices aimed at increasing productivity and improving the use of natural resources [7, 8]. Farmers in China, like their counterparts throughout the developing world, face new conditions brought about by such changes in sectoral policy as the lowering of trade barriers, limits on guaranteed prices, and reduced subsides on inputs such as seed, fertilizer, and irrigation water [9]. The need to conserve the natural resource base for agriculture is also becoming more acute. To respond effectively to these new conditions, farmers require technological options that maintain or increase productivity, reduce costs, and maintain production systems in a sustainable manner. Technological innovations must be monitored continuously to ensure that they meet these criteria. This article examines the role of a particular crop management innovation-planting summer maize on beds or furrows - in enabling farmers to meet the challenges of a changing socioeconomic and agroecological environment.

In this study, three planting patterns under rain-fed conditions in north China were used to investigate the effects of planting patterns on radiation-use efficiency, biomass accumulation and yield of summer maize.

\section{Materials and methods}

\subsection{Site and crops management}

The trial was conducted at agricultural experimental station of Shandong agricultural university in north China in 2005. The soil of the station is classified as clay. In 2005, three planting patterns were conducted, which were flat planting (D), bed planting (B) and furrow planting (F). For bed and furrow planting patterns, the distance between beds turned out to be $20 \mathrm{~cm}$, the height of the beds was $15 \mathrm{~cm}$. The width of the furrow between two beds was $20 \mathrm{~cm}$. For bed 
planting patterns, one row of summer maize was seeded on beds; for furrow planting patterns, one row of summer maize was seeded in furrows. The summer maize cultivar was "nongda 108", which was very popular in north China. The maize was sown on 7 June 2005, plant densities was $6.6 \times 10^{4}$ plants. $\mathrm{hm}^{-2}$. Weeds were controlled before emergence by application of Bentazon $\left(480 \mathrm{~g} \mathrm{l}^{-1}\right)$. Nitrogen and potassium fertilization were supplied so as to be non-limiting.

\subsection{Plant samples and measurements}

Plant samples were taken approximately every 10 days from emergence to maturity. Leaf measurements and calculations to obtain the green leaf area index (LAI) were used by SunScan. Above-ground dry matter was determined by sampling small plots consisting of 4 consecutive plants from the central rows. The sampling areas were spaced to avoid the effects of previous samplings. The 4 sampled plants were weighted (fresh weight). Dry matter was determined after drying at $80^{\circ} \mathrm{C}$ for $72 \mathrm{~h}$. Grain yield and yield components were measured at maturity on an area of $8 \mathrm{~m}^{2}$ corresponding to the two central rows of each plot. The number of maize ears per $\mathrm{hm}^{2}$ and the number of rows per ear were measured. The weight of 1000 grains was estimated by counting and weighting 100 grains on 3 replicates per plot. The harvest index (HI) was calculated by dividing the dry weight of grains by the aerial dry biomass at harvest.

\subsection{Canopy light interception and radiation-use efficiency}

In the later growing seasons of summer maize, the amount of solar radiation reaching the ground surface beneath the canopy was measured at three separate positions within each plot using SunScan every $1 \mathrm{~h}$. At the same time, incoming solar radiation above the crop canopy was also monitored. The difference between the above canopy and soil surface mounted by SunScan allowed for the determination of solar radiation intercepted by the canopy.

Radiation-use efficiency in the growing season of summer maize was calculated by [10]

$$
\mathrm{E} \%=\frac{\Delta W \cdot H}{\sum S} \times 100 \%
$$

In the above formula, $\triangle \mathrm{W}$ is dry matter weight at maturity; $\mathrm{H}=17.782 \mathrm{KJ} / \mathrm{g}$, is energy conversion coefficient; $\sum \mathrm{S}$ is global incoming radiation in the growing season of summer maize, which was recorded at the meteorological station of Tai'an located about $0.5 \mathrm{~km}$ of the experimental site.

\subsection{Statistical analysis}

The treatments were run as an analysis of variance (ANOVA). The ANOVA was performed at $\alpha=0.05$ level of significance to determine if significant differences existed among treatments means. The multiple comparisons were done for significant effects with the LSD test at $\alpha=0.05$. 


\section{Results}

\subsection{Leaf area index, light interception and radiation-use efficiency}

Mean seasonal change in leaf area index is presented in Figure 1. Leaf area index was similar for all treatments before anthesis. After anthesis, leaf-area index of bed and furrow planting patterns were higher than that of flat planting pattern, and post-anthesis green-area duration was longer under bed and furrow planting patterns. But little difference in leaf-area index between the bed and furrow planting patterns.

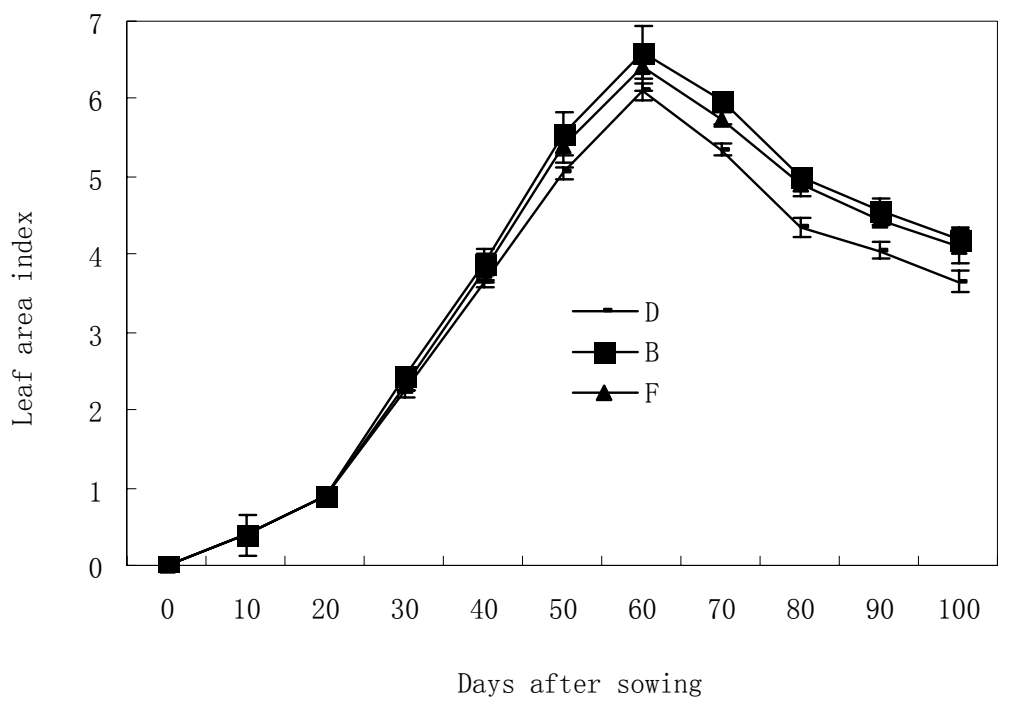

Figure 1: $\quad$ Seasoning change of leaf area index.

The proportion of the incident radiation intercepted by crop increased with leaf-area index, the amount of light intercepted by canopy of bed and furrow planting crops exceeded light interception by the canopy of the flat crop (Figure 2). Max light capture occurred in the bed and furrow treatment in the latter part of the season, but in the flat planting pattern, most incident light was transmitted to the soil surface. By contrast, the more even canopy of the bed and furrow planting crops captured more light and prevented its transmission to the soil surface. The impact of this may have been a reduction in heating of the soil surface in the bed and furrow planting crops, reducing the potential for loss of soil water via evaporation from the soil surface in this treatment.

Table 1 shows the radiation-use efficiency in the whole growing season of the three planting patterns, the calculated radiation-use efficiency corresponding to the furrow planting pattern did not appear to be significantly lower than that corresponding to the bed planting pattern, but the calculated radiation-use 
efficiency to the flat planting pattern did appear to be lower than those corresponding to the bed and furrow planting pattern. The substantial decrease in leaf area index during the whole growing seasons of the summer maize in flat planting pattern maybe cause a large reduction of the amount of PAR absorbed by the crop, therefore radiation-use efficiency in the whole growing season was significantly lower than those of bed and furrow planting patterns.

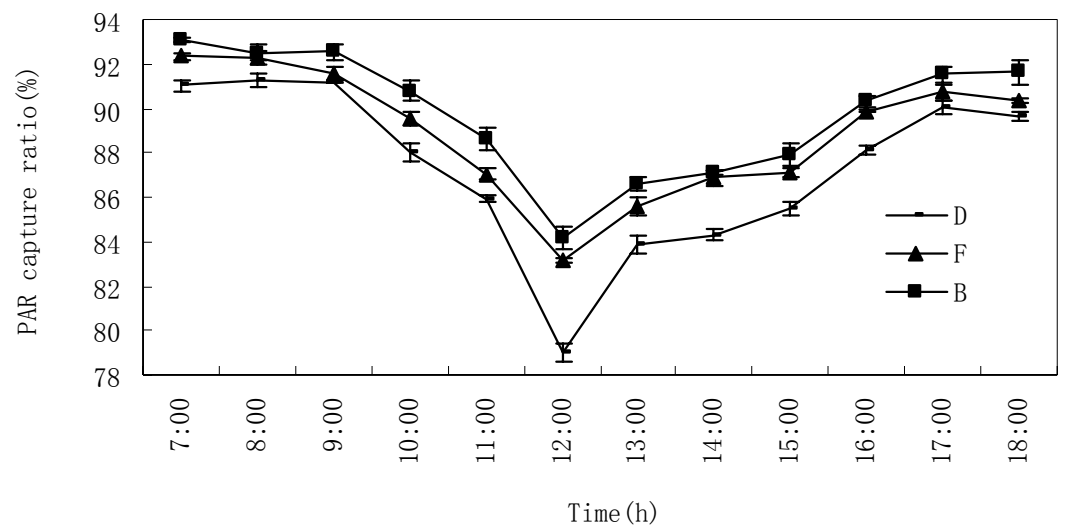

Figure 2: $\quad$ PAR capture ration in the daytime. The data was the mean value measured by SunScan on 19 Aug, 20 Aug and 22 Aug in 2005 (sunny day).

Table 1: Radiation-use efficiency in the whole growing season of flat, bed and furrow planting patterns.

\begin{tabular}{cc}
\hline Treatments & Radiation-use efficiency (\%) \\
\hline D & $2.41 \mathrm{~b}$ \\
B & $2.49 \mathrm{a}$ \\
F & $2.47 \mathrm{a}$ \\
\hline
\end{tabular}

Note: Within lines, means followed by the same letter are not significantly different $(\mathrm{P}<0.05)$. The same below.

\subsection{Above-ground biomass production}

Figure 3 shows the dry matter production after sowing for the three planting patterns. In the whole growing season, the above-ground biomass produced was very close between the bed and furrow planting patterns, no statistically significant differences were found. At maturity, dry matter was between 298 and $293 \mathrm{~g} / \mathrm{plant}$ for both planting patterns. In the flat planting pattern, the aboveground biomass production was reduced in the whole growing season, differences with the bed planting pattern were statistically significant $(\mathrm{P}=0.05)$ from the 5-visible leaf stage and onwards. At flowering, the biomass produced in 
flat planting pattern was $15.7 \%$ lower than that in bed planting pattern. At maturity, the above-ground biomass produced in the flat planting pattern was significantly lower than that in bed planting pattern. These were coincident with radiation-use efficiency, this means that the lower biomass produced in the flat planting pattern is mainly attributable to the lower amount of PAR absorbed by summer maize.

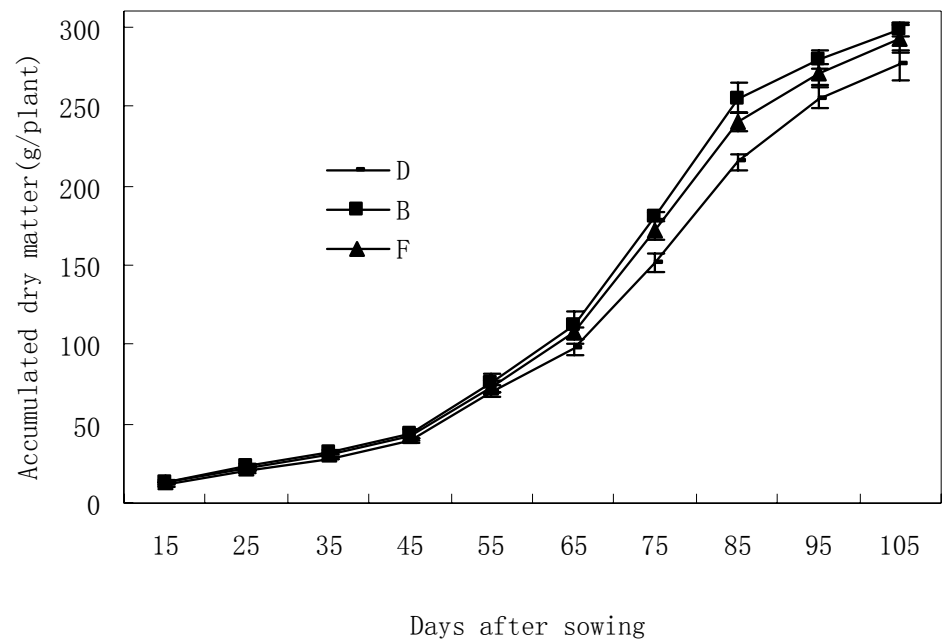

Figure 3: Changes in mean above-ground dry matter over the season.

Table 2: $\quad$ Maize yield and yield components of flat, bed and furrow planting patterns.

\begin{tabular}{llll}
\hline Treatment & D & B & F \\
\hline Number of rows per ear & $15.20 \mathrm{a}$ & $15.60 \mathrm{a}$ & $15.50 \mathrm{a}$ \\
Weight 1000 grains $(\mathrm{g})$ & $287.63 \mathrm{a}$ & $327.46 \mathrm{a}$ & $332.23 \mathrm{a}$ \\
$\begin{array}{l}\text { Number of maize ears } \\
\text { per hectare }\end{array}$ & $65790 \mathrm{a}$ & $65955 \mathrm{a}$ & $65895 \mathrm{a}$ \\
$\begin{array}{l}\text { Number of grains per } \\
\text { row }\end{array}$ & $35.43 \mathrm{~b}$ & $39.13 \mathrm{a}$ & $38.83 \mathrm{a}$ \\
Harvest index & $0.472 \mathrm{~b}$ & $0.514 \mathrm{a}$ & $0.508 \mathrm{a}$ \\
Yield $\left(\mathrm{kg} \mathrm{hm}^{-2}\right)$ & $9877.37 \mathrm{~b}$ & $11703.82 \mathrm{a}$ & $11421.13 \mathrm{a}$ \\
\hline
\end{tabular}

\subsection{Grain yield and yield components}

Table 2 gives the grain yields and yield components for the three planting patterns. Yield and yield components differed very little between the bed and furrow planting patterns. The average grain yield was only $2.5 \%$ higher in bed 
planting pattern than in furrow planting pattern. Conversely, grain yield was significantly $(\mathrm{P}=0.05)$ lower in flat planting pattern, the yield reduction was $15.6 \%$ and $13.5 \%$ of bed and furrow planting patterns. The number of grains per row was significantly lower in flat planting patterns than in bed and furrow planting patterns. The weight of 1000 grains, the number of maize ears per hectare and the number of rows per ear were not significantly different between any planting patterns. The harvest index was not different between bed and furrow planting patterns, but flat planting pattern was not, which suggest that planting patterns reduced grain production to the same extent as it reduced above-ground biomass production (Figure 3).

\section{Discussion}

In recent time, farmers have experimented with bed and furrow planting patterns not only in north China [11] but also throughout the world [12-14,16]. A major interest in these patterns is increasing water use efficiency in the growing season of crops $[13,17,18]$. In this article, the findings presented here show that bed and furrow planting patterns increase PAR capture ration in the whole growing season of summer maize, so decreased the evaporative loss of soil moisture from the ground surface, as a result, more soil moisture will be available for transpiration by the summer maize. This effect was ascribed to be mainly due to decreased penetration of incident radiation to the soil surface in the bed and furrow planting patterns.

Bed planting offers many advantages in irrigated wheat production systems $[11,14]$, and the authors are just beginning to determine how useful maize bed planting pattern may be for rain-fed areas, so did furrow planting pattern. We are confident that it can play an important role in environments characterized by prolonged waterlogging as a result of excessive rainfall.

As this paper has attempted to demonstrate, the potential for achieving sustainable increase in crops yield in China is still considerable, especially in north China, where population is very large, land and water resource are very short. Food security will depend not only on our ability to improve yield growth, but also on our ability to improve this yield growth in such a way that natural resource base remains unharmed. Agronomy and crop management research hold some of the most exciting opportunities for sustainably improving maize system productivity in areas such as north China. This paper has given some examples of planting patterns, whose adoption may make the difference between food security and resource scarcity in the years to come.

Providing farmers with viable management alternatives is the primary role of agricultural scientists. Bed and furrow planting patterns for summer maize go a long way towards achieving those goals.

\section{Acknowledgement}

Funding for this project was provided by the State Key Program of Basic Research of China ("973" Project, 2005CB121106). 


\section{References}

[1] Monteith, J. L. 1997. Climate and the efficiency of crop production in Britain. Trans. R. Soc. Lond. B. 281: 277-294.

[2] Kiniry, J. R., Jones, C. A., O'Toole, J. C., Blanchet R, Cabelguenne, M. and Spanel, D. A. 1989. Radiation-use efficiency in biomass accumulation prior to grain filling for five grain crop species. Field Crops Res. 20: 5164.

[3] Russelle, G., Jarvis, P. G. and Monteith, J. L. 1989. Absorption of radiation by canopies and stand growth. In Plant Canopies: Their Growth, Form and Function. Cambridge University Press, Cambridge, Ed. G Russell, pp21-39.

[4] Sinclair, T. R. and Muchow, R. C. 1999. Radiation-use efficiency. In Advances in Agronomy. Ed. D L Sparks (Ed.). pp 215-265. Academic Press, New York.

[5] Sinclair, T. R. and Horie, T. 1989. Leaf nitrogen, photosynthesis and crop radiation-use efficiency: A review. Crop Sci. 29: 90-98.

[6] Uhart, S. A. and Andrade, F. H. 1995. Nitrogen deficiency in maize: I . Effect on crop growth, development, dry matter partitioning and kernel set. Crop Sci. 35: 1376-1383.

[7] Dennis, W., David, C. and Garrick, S. 2002. Evaluating the impact of irrigation and drainage policies on agricultural sustainability. Irrigation and Drainage Systems. 16: 1-14.

[8] Ian, C., Mark, W. R. and David, S. 1997. Irrigation and food security in the $21^{\text {st }}$ century. Irrigation and Drainage Systems. 11: 83-101.

[9] Zhang, X. Y., Pei, D. and Hu, C. S. 2003. Conserving groundwater for irrigation in the North China Plain. Irrig. Sci. 21: 159-166.

[10] Li, Z. J., Li, F. C. and Zhao, B. Q. 1998. Studies on light and heat resource use efficiency and yield effect of wheat/corm/corn intercropping system. J. of Shandong Agricultural University. 29(4): 419-426.

[11] Wang, F. H., Wang, X. Q. and Ken S. 2004. Comparison of conventional, flood irrigated, flat planting with furrow irrigated, raised bed planting for winter wheat in China. Field Crops Res. 87: 35-42.

[12] Abu-Awwad, A. M. 1999. Effects of sand column, furrow and supplemental irrigation on agricultural production in an arid environment. Irrig. Sci. 18:191-197.

[13] Panigrahi, B., Panda, S. N. and Raghuwanshi, N. S. 2001. Potato water use and yield under furrow irrigation. Irrig. Sci. 20: 155-163.

[14] Agustin Limon-Ortega., Sayre, K. D. and Francis, C. A. 2000. Wheat and maize yields in response to straw management and nitrogen under a bed planting system. Agronimy J. 92: 295-302.

[15] Kang, Y. H., Wang, Q. G. and Liu, h. J. 2005. Winter wheat canopy interception and its influence factors under sprinkler irrigation. Agricultural Water Management. 74: 189-199.

[16] Dean, D. S., Earl, C. S. and Raymond, E. K. 2000. Irrigation management for corn in the northern Great Plains, USA. Irrig. Sci. 19: 107-114. 
[17] Wang, R. Z. and Gao, O. 2001. Photosynthesis, transpiration, and water use efficiency in two divergent Leymus chinensis populations from Northeast China. Photosynthetica. 39(1): 123-126.

[18] Mishra, H. S., Rathore, T. R. and Savita, U. S. 2001. Water-use efficiency of irrigated winter maize under cool weather conditions of India. Irrig. Sci. 21:27-33. 